\title{
On the Fatigue Strength Improvement Factor for High Frequency Mechanical Impact Treatment Method
}

\author{
Balázs József Mecséri1 ${ }^{1 *}$, Balázs Kövesdi \\ ${ }^{1}$ Department of Structural Engineering, Faculty of Civil Engineering, Budapest University of Technology and Economics, H-1111 \\ Budapest, Műegyetem rkp. 3., Hungary \\ * Corresponding author, e-mail: mecseri.balazs@epito.bme.hu
}

Received: 08 October 2019, Accepted: 25 March 2020, Published online: 22 April 2020

\begin{abstract}
Nowadays, the most commonly applied post weld treatment method improving fatigue strength of welded structures is the High Frequency Mechanical Impact (HFMI) treatment method. However, the treatment process is already well-known and widely used, there are several unanswered questions about its impact on the mechanical properties and fatigue behavior of treated welded structures. For understanding the mechanical background of the fatigue properties of HFMI-treated, welded, normal and high strength steel structures, it is necessary to analyze fatigue test results from many different aspects. According to previous studies it can be observed that fatigue strength of HFMI-treated steel specimens increases with the yield strength of base material. However, the fatigue strength of as-welded details is independent of the steel grade; thus if yield strength increases, fatigue strength improvement factors (ratio between the fatigue strengths of as-welded and HFMI-treated specimens) of HFMI-treated steel specimens should increase as well. In this paper, the relationship between steel grade and fatigue strength improvement factors of HFMI-treated details is investigated by using previous experimental results. A large number of previous experimental results are revised by the authors; published test results were collected and re-evaluated. Using the analyzed measures, the effect of HFMI treatments was analyzed. Fatigue strength improvement factor related to HFMI is calculated for two different types of structural details (cruciform joints and longitudinal attachments). For both cruciform and longitudinal joints, it is observed that the improvement factor decreases with increasing yield strength.
\end{abstract}

Keywords

high frequency mechanical impact (HFMI), high strength steel, fatigue strength improvement, weld toe

\section{Introduction}

In fatigue design of welded structural details, the High Frequency Mechanical Impact (HFMI) methods are the most favorable and productive post weld treatment methods in the current engineering practice. Numerous previous studies and research activities investigated the different application possibilities of weld treatment methods. The fatigue behavior and lifetime properties of treated structural details were previously analyzed by experimental and numerical tools in a detailed manner. However, more experimental results are required for a better understanding of fatigue strength improvement effect of weld treatment methods. The main aim of the current paper is to re-analyze numerous previous experimental results and to get new observations about the effects of these weld treatment methods. This study focuses on the relationship of the base material yield strength and the HFMI improvement factor. To apply high strength steels (HSS) in fatigue sensitive structures, HFMI-treatment can be a good solution. Nowadays, it is accepted, that the fatigue strength of as-welded structural details are independent from the steel grade. Thus, if HSS material is applied in a structure, where fatigue is the governing limit state, the resistance of the structure is the same as the one made of normal strength steel (NSS). In order to economically apply HSS in fatigue sensitive structures it is necessary to increase their fatigue strength. A possible solution is applying post weld treatment methods. It can be a weld geometry improvement method, which can reduce the stress peaks caused by local geometry of weld and can remove undercuts and weld defects. Other weld treatment methods are the so-called residual stress methods, which have the same advantages as the weld geometry improvement method, moreover they introduce residual compression stresses into the welded zone. HFMI treatment method belongs to 
the residual stress methods, and they have an additional benefit. Based on previous studies, the fatigue strength of HFMI-treated details is not the same for all steel grades. By increasing yield strength, fatigue strength increases as well. The current paper has the aim to investigate this favorable phenomenon and to check the efficiency of this treatment method for different steel grades. Calculating and analyzing the fatigue strength improvement factors, the effect of HFMI treatment is investigated from different perspective, and background of the fatigue strength increase is understood and explained more substantial.

\section{Literature review}

\subsection{HFMI treatment methods and their effect on fatigue strength}

Different types of high frequency mechanical impact treatment methods are known nowadays [1]. Names of different types of devices are as follows: ultrasonic impact treatment (UIT) [2], high frequency impact treatment (HiFiT), pneumatic impact treatment (PIT) [3], ultrasonic peening treatment (UPT) [4, 5] and ultrasonic needle peening (UNP) [6]. At first UIT was developed by the Northern Scientific and Technological Foundation (Russia) and Paton Welding Institute (Ukraine) and proposed by Statnikov [7] in the early 1970s. The principle of all HFMI techniques (Fig. 1) is identical: cylindrical indenters are accelerated against the region to be treated with high frequency (approximately $90 \mathrm{~Hz}$ ). They are residual stress modification methods, which means that they can eliminate weld toe flaws and defects, reduce local stress concentrations and eliminate tensile residual stresses in treated regions and induce compressive residual stresses. Researchers proved in the past that this approach increases the fatigue strength and lifetime of welded structural details. The treatment method introduces compressive residual stresses in fatigue critical points decreasing the local mean stress in the surrounding region. Therefore, it leads to increase in the crack initiation part of the fatigue lifetime.

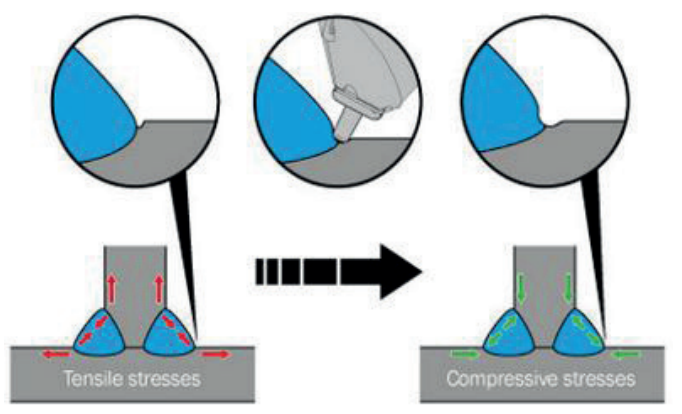

Fig. 1 The process and effect of HFMI treatment [6]
In the previous twenty years, numerous experimental programs were conducted with the aim to investigate and analyze the fatigue behavior of as-welded and HFMItreated, normal and high strength steel specimens. According to the previous studies [8-16] it has been observed that HFMI post weld treatment methods are more favorable in case of high strength steel specimens than for normal strength steel structures. It means that increasing yield strength of the base material increases the fatigue strength, which would not happen for non-treated specimens. Based on the test results of German experimental research programs, Weich [8] proposed a formula to estimate the lifetime increasing effect of HFMI treatment method. The same phenomenon was investigated by Yildirim and Marquis [1]. In their study, three types of structural details were investigated (longitudinal attachment, butt joint and cruciform joint) and three different formulas were supervised, which can describe the effect of yield strength on fatigue strength of HFMI-treated structural details.

The currently analyzed database is taken from previously published papers and research reports (inclusive of Weich's work [8]). All test results belong to fatigue tests at constant amplitude fatigue loading with $R=0.1$. The test results were plotted in a $\log S-\log N$ system, and regression lines with a slope of $m=5$ were used comparing HFMI results with fatigue detail class of IIW recommendations. The study confirmed the former statements and assumptions that increasing yield strength increases the difference between FAT of as-welded and HFMI-treated details. Confirming these results Yildirim and Maqius [1] proposed various FAT class increasing factors for different steel grades, which are given in Fig. 2.

The slope $(m)$ of standardized $S$ - $N$ curves for as-welded specimens is equal to 3. However, for HFMI-treated details $m=5$ gives the best approximation. Therefore, a recent set of $S$ - $N$ curves was necessary to calculate fatigue lifetime of HFMI-treated structural details. The proposed $S-N$ curves can be found in the IIW recommendations $[17,18]$.

However, in most previous experimental research programs the regression lines of $S-N$ diagrams were determined by the method of the least squares, and the fatigue strength improvement factors were only calculated for the actual test data set. In Weich's [8, 19] and Yildirim's $[1,20,21]$ research programs the favorable fatigue properties of HFMI-treated high strength steel details come from the analysis, where the fatigue strengths are calculated from regression lines with a forced slope of $m=5$. In these cases, it can be observed that the $S$ - $N$ curve of 
treated details from higher steel grade have higher fatigue strength. Yildirim and Marquis [1] compared the experimental $S$ - $N$ curves of HFMI-treated specimens from different steel grades using the recommended [22] $S$ - $N$ curves of as-welded specimens. Their conclusion was that for specimens loaded by $R=0.1$ constant amplitude fatigue load, fatigue strength increase can be observed, which increase depends on the yield strength. Yildirim and Marquis proposed a calculation method for HFMI-treated specimens in which $f_{y}=355 \mathrm{MPa}$ yield strength is taken as reference value. An amount of $200 \mathrm{MPa}$ increase in yield strength causes approximately $12.5 \%$ increase in fatigue strength (Fig. 2). This fatigue life calculation method was adopted by IIW as well. It means that determining the fatigue resistance of an arbitrary structural detail, the FAT of an original, as-welded detail increases by applying weld improvement method; the rate of increase depends on the yield strength.

\subsection{Published experimental results}

The fatigue data of 8 publications were collected by the authors and re-analyzed. From these studies 331 fatigue test results could be gathered which belong to 8 different steel grades $[23,24]$. The collected cruciform specimens have different dimensions, but the loading procedures are the same for all experimental program. Yekta's specimens [23] were fabricated from CSA grade $350 \mathrm{~W}$ steel with a thickness of $9.5 \mathrm{~mm}$. The cruciform specimen was made with a width of $50 \mathrm{~mm}$ and length of $400 \mathrm{~mm}$. Two transverse stiffeners were welded on the base plate. The HFMI-treated specimens were "dog-boned" before tests. The HFMI treatment was conducted with a speed of $10 \mathrm{~mm} / \mathrm{s}$ and an amplitude of $\sim 28 \mu \mathrm{m}$. In study of Okawa et al. [25] the investigated specimens are made from AH36 shipbuilding high-strength steel. The length

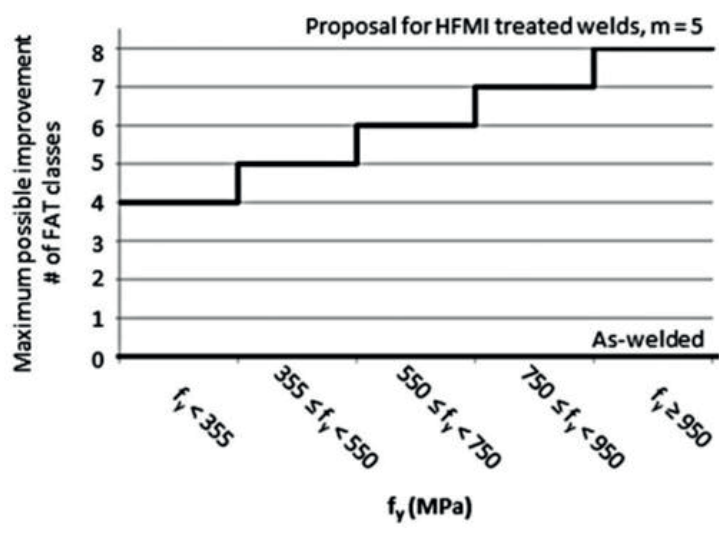

Fig. 2 Improvement effect of HFMI treatment method [1] of the specimens was $700 \mathrm{~mm}$, their width was $75 \mathrm{~mm}$. The applied thickness was $20 \mathrm{~mm}$. The UIT equipment was an Esonix 27 with a 3-mm-diameter indenter. Kuhlmann [26] studied specimens with length of $450 \mathrm{~mm}$, width of $80 \mathrm{~mm}$ and a thickness of $12 \mathrm{~mm}$. Their specimens were fabricated from S355J2 and S690QL grade structural steels. The HFMI treatment was a so-called PITTechnologie. The diameter of the indenter was $8 \mathrm{~mm}$, and the applied speed of treatment was $20-30 \mathrm{~cm} / \mathrm{min}$. All the investigated cruciform specimens were loaded by $\mathrm{R}=0.1$ constant amplitude axial cyclic load. All the experimental programs studied the effect of HFMI weld treatment method on the fatigue strength of analyzed specimens. In the current paper stress range - fatigue lifetime results are collected and re-analyzed to get better understanding of mechanical properties of HFMI treatment methods.

The test results of investigated longitudinal attachments were collected from other different papers as well. Lihavainen et al. [27] investigated this type of specimens with a length of $600 \mathrm{~mm}$, width of $34 \mathrm{~mm}$ and thicknesses of 5 and $8 \mathrm{~mm}$ as well. The applied steel grade was S355J0. The weld toes were treated by UIT type HFMI-treatment. The diameter of indenter was $3 \mathrm{~mm}$, and the depth of treated groove was approximately $0.5 \mathrm{~mm}$. In study of Huo et al. [28] the specimens were fabricated from 16Mn steel plates with a thickness of $8 \mathrm{~mm}$. The investigated specimens had a length of $190 \mathrm{~mm}$ and a width of $40 \mathrm{~mm}$. The HFMI treatment was an ultrasonic peening method and the applied speed was $1.2 \mathrm{~m} / \mathrm{min}$. Mori et al. [29] tested specimens from three different steel grades: SBHS400, SBHS500 and SBHS700. The steel materials are specified in the Japan Industrial Standard (JIS). The specimens were made from plates with a thickness of $12 \mathrm{~mm}$. HFMI treatment was carried out using Esonix 27 by Applied Ultrasonics. The depth of treated groove was about $0.25 \mathrm{~mm}$. Weich [30] studied specimens made from S690QL steel material. The specimens had $872 \mathrm{~mm}$ length and $60 \mathrm{~mm}$ width, treated HiFIT and UIT processes. The diameter of indenters was $3 \mathrm{~mm}$ for both methods, and the speed was $3 \mathrm{~mm} / \mathrm{s}$ and $8.3 \mathrm{~mm} / \mathrm{s}$ for HiFIT and UIT methods, respectively.

These two types of structural details are investigated in the current paper; these details were frequently researched in the past. Fatigue test results for cruciform joints and longitudinal attachments are collected and the sources are summarized in Tables $1-2$. In the current study it is important to mention that all resource contains test results for HFMI-treated and as-welded specimens as well. Therefore, the fatigue strength improvement factors for 
Table 1 Published and reinvestigated test results for cruciform joints

\begin{tabular}{lcccc}
\hline Ref. & $\begin{array}{c}\text { Steel } \\
\text { grade }\end{array}$ & $f_{y}$ [MPa] & $\begin{array}{c}\text { Treatment } \\
\text { method }\end{array}$ & $t[\mathrm{~mm}]$ \\
\hline Yekta [23] & $350 \mathrm{~W}$ & 350 & UIT & 9.5 \\
Okawa et al. [25] & AH36 & 392 & UIT & 20 \\
Kuhlmann et al. [24] & S355 & 398 & UIT & 12 \\
Kuhlmann [26] & S355 & 477 & PIT & 12 \\
Kuhlmann et al. [24] & S460 & 504 & UIT & 12 \\
Kuhlmann [26] & S690 & 781 & PIT & 12 \\
Kuhlmann et al. [24] & S690 & 830 & UIT & 12 \\
\hline
\end{tabular}

Table 2 Published and reinvestigated test results for longitudinal attachments

\begin{tabular}{lcccc}
\hline Ref. & $\begin{array}{c}\text { Steel } \\
\text { grade }\end{array}$ & $\begin{array}{c}\text { fy } \\
{[\mathrm{MPa}]}\end{array}$ & $\begin{array}{c}\text { Treatment } \\
\text { method }\end{array}$ & $\mathrm{t}[\mathrm{mm}]$ \\
\hline Lihavainen et al. [27] & S355 & 355 & UIT & 5 and 8 \\
Huo et al. [28] & $16 \mathrm{Mn}$ & 390 & UPT & 8 \\
Mori et al. [29] & SBHS400 & 456 & UIT & 12 \\
Mori et al. [29] & SBHS500 & 572 & UIT & 12 \\
Weich [30] & S690 & 719 & UIT and & 16 \\
Mori et al. [29] & SBHS700 & 753 & UIFIT & 12 \\
\hline
\end{tabular}

these specimens can be unambiguously determined and investigated. The yield strength $\left(f_{y}\right)$ of the applied steel grades varied between 350 to $830 \mathrm{MPa}$. Specimen thickness $(t)$ varied between 5 to $20 \mathrm{~mm}$. All run-out fatigue test results are ignored in the current analysis, results of failed specimens are only considered for evaluation.

\section{Evaluation of previous fatigue test results}

\subsection{Determination of experimental $S-N$ curves of collected tests}

For both cruciform joints and longitudinal attachments, the experimental $S$ - $N$ curves of as-welded and HFMI-treated specimens are determined. For calculations and investigations, the nominal values of the stress ranges are applied. Regression lines of as-welded results are determined with a forced slope of $m=3$, as suggested by IIW recommendations [22]. The slope of HFMI-treated $S-N$ curves is assumed to be equal by $m=5$, as recommended by Marquis and Barsoum [17] and previous research results [10, 20]. The regression lines and fatigue test results for cruciform joints are shown on Fig. 3.

The experimental $S-N$ curves are plotted and evaluated based on nominal stresses and measured fatigue lifetimes. In all cases red sign shows the as-welded and blue signs mark the HFMI-treated fatigue test results. The source of the data can be found in Tables 1-2. Regression lines are

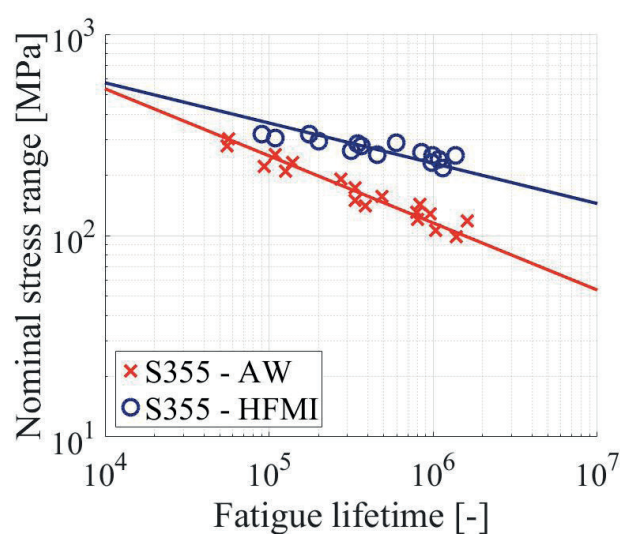

(a)

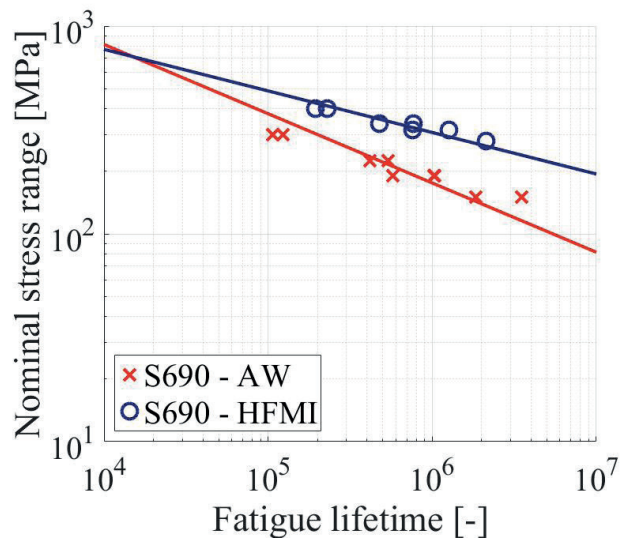

(b)

Fig. 3 S-N curves of typical (a) NSS specimens (Kuhlmann's experiments [24]) and (b) HSS specimens (Kuhlmann's experiments [26])

calculated by least square method. For the as-welded and HFMI-treated specimens regression line slope of $m=3$ and $m=5$ is fixed, respectively. The presented diagrams prove that regression lines show good agreement with the data points for cruciform joints. Thus, the analysis of fatigue behavior of as-welded and HFMI-treated specimens can be made by the determined regression lines. The calculated fatigue strengths (stress range at $2 \times 106$ cycles) based on the regression lines are summarized in Table 3.

Table 3 Calculated fatigue strengths for cruciform as-welded and HFMI-treated joints

\begin{tabular}{lccc}
\hline Ref. & $\begin{array}{c}\text { Steel } \\
\text { grade }\end{array}$ & $\begin{array}{c}\text { Fatigue } \\
\text { strength - AW }\end{array}$ & $\begin{array}{c}\text { Fatigue strength } \\
\text { - HFMI }\end{array}$ \\
\hline Yekta [23] & 350W & 97.2 & 242.79 \\
Okawa et al. [25] & AH36 & 86.0 & 220.06 \\
Kuhlmann et al. [24] & S355 & 91.2 & 198.95 \\
Kuhlmann [26] & S355 & 109.6 & 226.4 \\
Kuhlmann [24] & S460 & 100.7 & 207.76 \\
Kuhlmann [24] & S690 & 132.5 & 221.41 \\
Kuhlmann [26] & S690 & 139.4 & 267.7 \\
\hline
\end{tabular}


The regression lines and experimental results for longitudinal joints are presented on Fig. 4. The calculated fatigue strengths are presented in Table 4. According to the diagrams it can be recognized that regression lines with $m=5$ slope are less accurate for longitudinal attachments, however the recommendations prescribe this value, therefore, it is used for the further investigations.

There are some cases, where the as-welded and HFMItreated specimens are loaded by the same stress range, however in other cases results of as-welded and HFMItreated specimens are located in the same fatigue lifetime

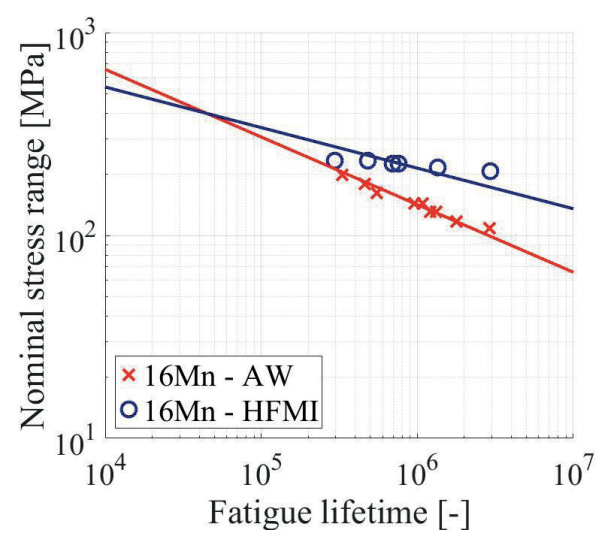

(a)

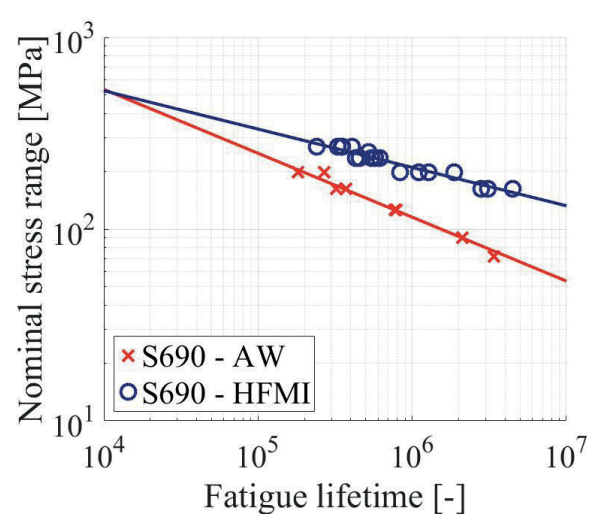

b)

Fig. $4 S$ - $N$ curves of typical (a) NSS specimens (Huo's experiments [28]) and (b) HSS specimens (Weich's experiments[30])

Table 4 Calculated fatigue strengths for longitudinal as-welded and HFMI-treated joints

\begin{tabular}{lccc}
\hline Ref. & $\begin{array}{c}\text { Steel } \\
\text { grade }\end{array}$ & $\begin{array}{c}\text { Fatigue } \\
\text { strength - AW }\end{array}$ & $\begin{array}{c}\text { Fatigue strength } \\
\text { - HFMI }\end{array}$ \\
\hline Lihavainen et al. [27] & S355 & 79.8 & 173.8 \\
Huo et al. [28] & 16Mn & 112.6 & 186.8 \\
Mori et al. [29] & SBHS400 & 85.3 & 109.5 \\
Mori et al. [29] & SBHS500 & 84.4 & 114.6 \\
Weich [30] & S690 & 91.5 & 182.5 \\
Mori et al. [29] & SBHS700 & 87.1 & 119.0 \\
\hline
\end{tabular}

regions with different loading stress ranges. Therefore, it is not always possible to select as-welded - HFMI-treated pairs from previously defined stress ranges or fatigue life regions for further investigations.

Therefore, the comparison is performed on the level of data points (regression lines) only. It is important to mention that all experiments from different research programs are analyzed separately, thus the effect of different environment, temperature, loading machines and other influencing factors can be neglected. It means that HFMI weld treatment is the only effect, which influences the fatigue lifetime increase and the magnitude of the improvement factor.

\subsection{Determination of fatigue strength improvement factors}

To compare the effect of HFMI treatment method on different steel grades, the improvement factors are determined for all different experimental programs. The comparison of treated and untreated results can be calculated by two different ways. One of them is, when regression lines of all data sets are determined, and based on these $S$ - $N$ curves the fatigue strength $\left(N_{f}=2 \times 106\right)$ are calculated (Fig. 5, Table 5 and Table $6-f_{b}$ ). The ratio of HFMI-treated fatigue

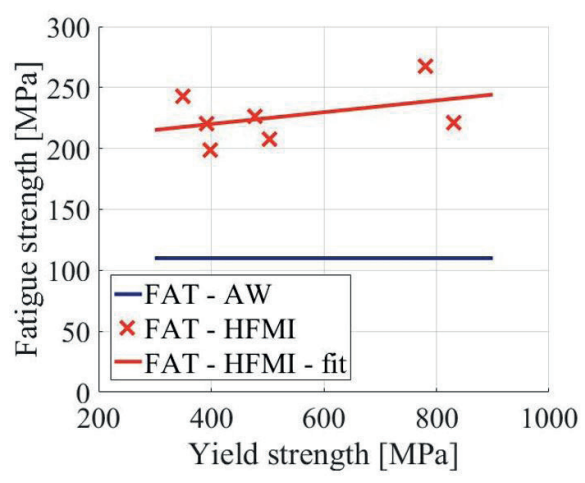

(a)

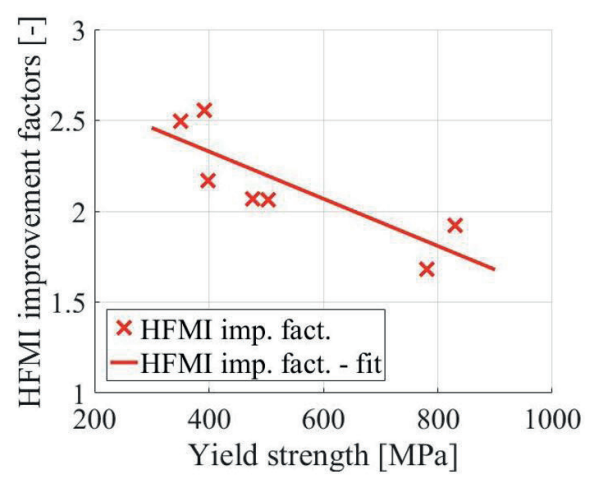

(b)

Fig. 5 (a) FAT of HFMI-treated specimens and (b) HFMI improvement factors for cruciform joints 
Table 5 Calculated fatigue strength improvement factors of HFMI treatment for cruciform joints

\begin{tabular}{lccc}
\hline Ref. & $\begin{array}{c}f_{y} \\
{[\mathrm{MPa}]}\end{array}$ & $\begin{array}{c}\text { Improvement } \\
\text { factors based on } \\
\text { single points } \\
f_{a}\end{array}$ & $\begin{array}{c}\text { Improvement } \\
\text { factors based on } \\
\text { regression lines } \\
f_{b}\end{array}$ \\
\hline Yekta [23] & 350 & 2.506 & 2.497 \\
Okawa et al. [25] & 392 & 2.561 & 2.557 \\
Kuhlmann et al. [24] & 398 & 2.188 & 2.170 \\
Kuhlmann [26] & 477 & 2.102 & 2.065 \\
Kuhlmann et al. [24] & 504 & 2.090 & 2.065 \\
Kuhlmann [26] & 781 & 1.729 & 1.681 \\
Kuhlmann et al. [24] & 830 & 1.941 & 1.920 \\
\hline
\end{tabular}

Table 6 Calculated fatigue strength improvement factors of HFMI treatment for longitudinal attachments

\begin{tabular}{lccc}
\hline Ref. & $\begin{array}{c}f_{y} \\
{[\mathrm{MPa}]}\end{array}$ & $\begin{array}{c}\text { Improvement } \\
\text { factors based on } \\
\text { single points } \\
f_{a}\end{array}$ & $\begin{array}{c}\text { Improvement } \\
\text { factors based on } \\
\text { regression lines } \\
f_{b}\end{array}$ \\
\hline Lihavainen et al. [27] & 355 & 2.247 & 2.178 \\
Huo et al. [28] & 390 & 1.670 & 1.660 \\
Mori et al. [29] & 456 & 1.305 & 1.284 \\
Mori et al. [29] & 472 & 1.396 & 1.357 \\
Weich [30] & 719 & 1.660 & 1.994 \\
Mori et al. [29] & 753 & 1.361 & 1.367 \\
\hline
\end{tabular}

strength to as-welded fatigue strength can demonstrate the improvement effect of HFMI treatment. The idea of the other approach is to create test result pairs, which belong to each other; thus, the improvement effect can be analyzed for unique cases. Creating result pairs can be made based on separation of test results according to stress ranges (specimens are loaded with the same amplitude) or number of cycles (specimens have approximately the same fatigue lifetime). However, there is no acceptable pairing technics for all investigated experimental results. Therefore, a third coupling method is chosen for data analysis by the authors. All as-welded results are compared to all HFMI-treated specimens. A regression line is fitted to all as-welded (with the slope of $m=3$ ) and HFMI-treated (with a slope of $m=5$ ) test results. The fatigue strength from all regression lines are calculated $\left(\mathrm{Nf}=2 \times 10^{6}\right)$ and all as-welded values are compared to the treated ones. Thus an improvement factor for all possible as-welded - HFMI-treated pairs could be calculated (blue dots - Fig. 6). For every research program the improvement factors are calculated by simple averaging of the calculated improvement factors from all as-welded - HFMI-treated pairs (Table 5 and Table $6-f_{a}$ ). The results show that fatigue lifetime increasing effect of HFMI

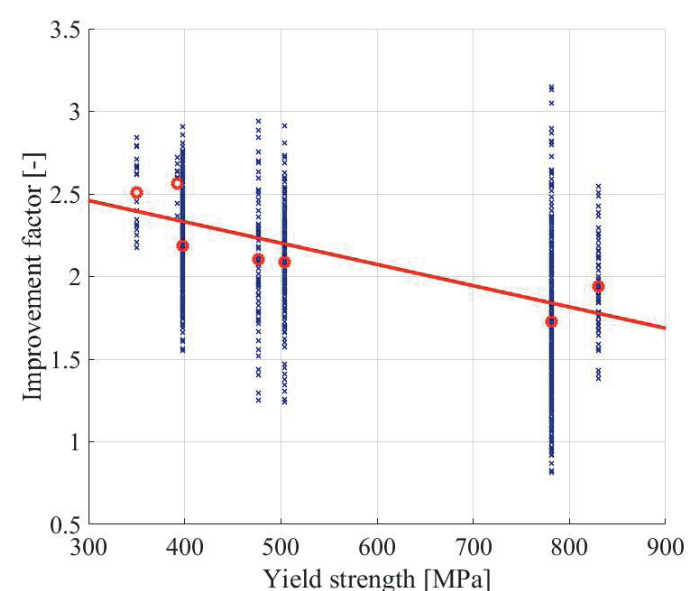

(a)

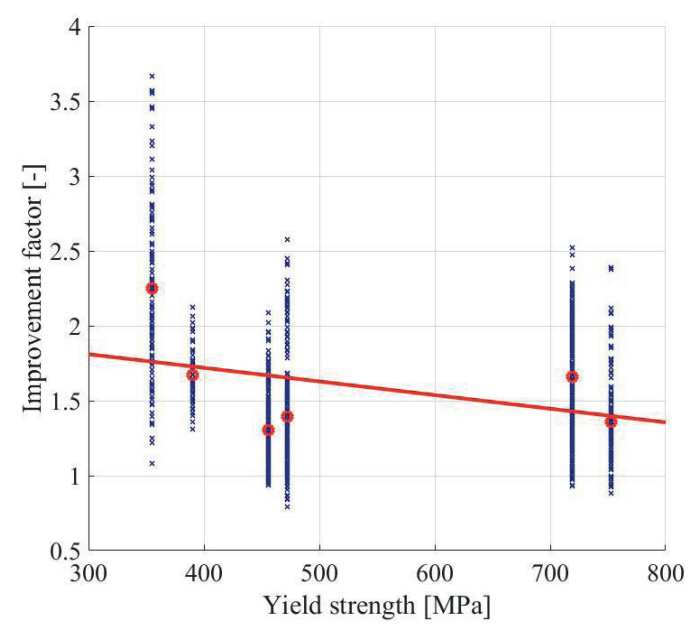

(b)

Fig. 6 HFMI improvement factors plotted against yield strength for (a) cruciform joints and b) longitudinal attachments

treatment has a large scatter (between 1.5-2.5). It means approximately $60 \%$ difference between the investigated steel grades. The question is the following. Is there any relationship between the rate of fatigue strength improvement and the yield strength of the applied steel materials?

\section{Evaluation and discussion of test results}

Investigating the fatigue strength of HFMI-treated specimens, it can be observed that there is a relationship between HFMI-treated fatigue strength and yield strength (Fig. 5(a)). According to this phenomenon, it can be stated that fatigue strength of HFMI-treated details increases with the yield strength [1]. However, there is another aspect; during design the effect of HFMI treatments is taken into consideration with an improvement factor. This factor shows the fatigue strength ratio of HFMI-treated and as-welded details, but this value is not calculated directly from experimental results. In this study, the improvement factors are calculated 
from fatigue test results, and only coherent results are considered. Namely, an improvement factor is determined only from one test procedure applying the same steel grade. This improvement factors are plotted against the yield strength of investigated steel material (Fig. 5(b)). Analyzing Fig. 5(b) an interesting phenomenon can be observed; improvement factor decreases with increasing yield strength, despite the fatigue strength increases, as shown in Fig. 5(a).

Investigating all previously mentioned as-welded test results (Table 1 and Table 2) a common regression line (Fig. 7(a)) and standard error of regression are determined. Putting in context these parameters are calculated for HFMI-treated (Fig. 7(b)) specimens as well.

The standard error of regression for as-welded results is 0.102 , for HFMI-treated results it is 0.060 . Therefore, it can be stated that a common $S$ - $N$ curve can be fitted more accurately for HFMI-treated results, than for as-welded results.

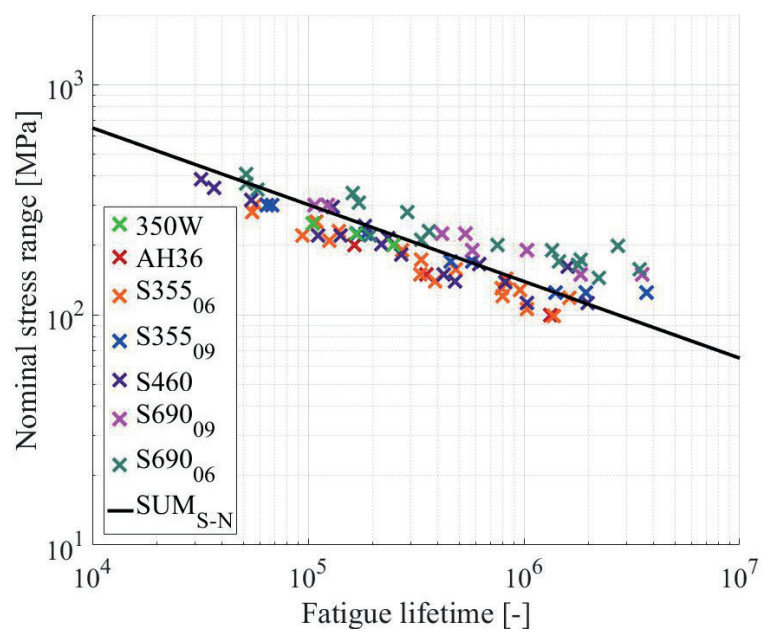

(a)

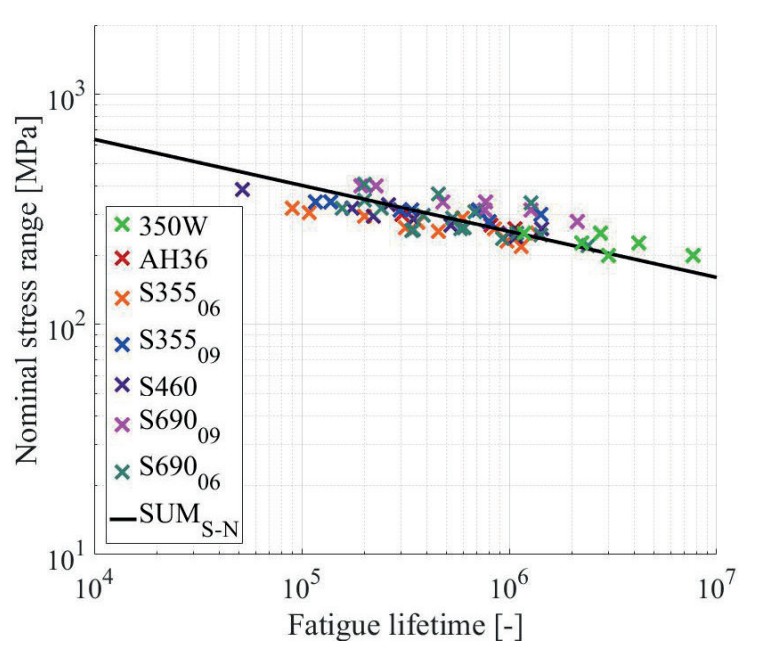

(b)

Fig. 7 Test results and fitted common $S$ - $N$ curves of (a) as-welded and (b) HFMI-treated specimens
Moreover, the current IIW recommendations say that the fatigue strength of HFMI-treated structural details increases by increasing yield strength. On the other hand, the presented calculations show that the fatigue improvement factors decrease by increasing yield strength. The consequence of these two phenomena is that the fatigue strength of as-welded structural details cannot be independent of the yield strength, according to the observations it increases with increasing yield strength. This statement is supported by study of Harati et al. [14], in which the fatigue properties of a welded $1300 \mathrm{MPa}$ yield strength steel was investigated. Harati found that the fatigue strength of as-welded details is significantly higher, than the standard value [14]. However, the improvement factor of HFMI treatment is only 1.26.

\section{Conclusions}

Summarizing the current investigation on the relationship of HFMI treatment improvement factors and yield strength, the following statements are concluded. The fatigue lifetime increase due to weld treatment methods is a complex problem, where the analysis methods can have effect on the final conclusions. Re-analyzing results of previously conducted fatigue research programs a new comparison method is applied and presented in the current paper. The results of coherent as-welded - HFMI-treated specimens are compared and the fatigue lifetime increasing effects are determined and evaluated. The improvement factors of HFMI treatment show interesting properties, which are the followings:

- According to previous fatigue test results of as-welded and HFMI-treated cruciform joints, it can be stated that the HFMI improvement factor decreases with increasing yield strength. The fatigue strength improvement factor is approximately $f=2.5$ for the lowest investigated steel grade $(350 \mathrm{~W})$ and $f=1.7$ for the highest steel grade (S690).

- Based on the test results of longitudinal attachments the same trend can be observed. The lowest improvement factor $(f=1.35)$ belongs to the steel grade with highest yield strength (SBHS700), the regression line has negative slope (Fig. 6), similar to cruciform details; the highest improvement factor $(f=2.2)$ belongs to the lowest steel grade (S355).

- According to the given results, it can be observed that the efficiency of HFMI treatment decreases with increasing yield strength. That means applying HFMI treatment is more economic for specimens which are made from lower steel grades. 
- Based on the investigation of different steel grades, the increasing fatigue strength of HFMI-treated details and the decrease of improvement factors can be possible, when the fatigue strength of as-welded details increases by increasing yield strength. Thus, the fatigue strength of as-welded structural details cannot be independent of steel grade.

To understand the behavior of HFMI post weld treatment method numerous new experiments would be necessary. For further research program, it is important that as-welded and HFMI-treated specimens should be investigated together using the same manufacturing process and

\section{References}

[1] Yildirim, H. C., Marquis, G. B. "Fatigue strength improvement factors for high strength steel welded joints treated by high frequency mechanical impact", International Journal of Fatigue, 44, pp. 168176, 2012.

https://doi.org/10.1016/j.ijfatigue.2012.05.002

[2] Applied Ultrasonics "Improving Fatigue Strength of Welded Joints by Ultrasonic Impact Treatment" [pdf] Available at: http:// www.appliedultrasonics.com/pdf/IMPROVING-FATIGUESTRENGTH-OF-WELDED-JOINTS-BY-ULTRASONICIMPACT-TREATMENT.pdf [Accessed: 20 March 2020]

[3] Pitec "HFMI - the advantages of PIT" [online] Available at: https:// www.pitec-gmbh.com/application/files/8715/8315/7797/HFMIthe_advantages_of_PIT_Vs.8.pdf [Accessed: 20 March 2020]

[4] Lets Global "Ultrasonic Peening Treatment" [online] Available at: http://lets-global.com/ultrasonic-peening-2/ [Accessed: 20 March 2020]

[5] Integrity Testing Laboratory Inc. "Equipment UltraPeen for Ultrasonic Peening of Parts \& Welded Elements" [online] Available at: https://itlinc.com/equipment-ultrapeen-for-ultrasonic-peening-of-parts-welded-elements/ [Accessed: 20 March 2020]

[6] Sonats "Ultrasonic weld impact treatment - HFMI/UIT" [online] Available at: https://sonats-et.com/en/hfmi-treatment/ultrasonic-impact-treatment/ [Accessed: 20 March 2020]

[7] Statnikov, E. "Physics and Mechanism of Ultrasonic Impact Treatment", Applied Ultrasonics, Albertville, AL, USA, IIW Document XIII-2004-04, 2004. [online] Available at: http://www. appliedultrasonics.com/pdf/physics.pdf [Accessed: 20 March 2020]

[8] Weich, I. "High frequency hammer peening design", presented at The International Institute of Welding (IIW) Congress, Tehran, Iran, Nov, 30 - Dec, 3, 2009.

[9] Bignonnet, A. "Improving the fatigue strength of welded steel structures", In: Proceedings of the 3rd International ECSC Offshore Conference on Steel in Marine Structures, Delft, Netherlands, 1987, pp. 99-118.

[10] Zhao, X., Wang, D., Huo, L. "Analysis of the S-N curves of welded joints enhanced by ultrasonic peening treatment", Materials and Design, 32(1), pp. 88-96, 2011 https://doi.org/10.1016/j.matdes.2010.06.030 loading conditions. Thus, the number of test parameters can be decreased, and more accurate information could be given on the fatigue properties of HFMI-treated structural details.

\section{Acknowledgement}

The executed research program was supported by the ÚNKP-18-4 New National Excellence Program of the Ministry of Human Capacities of Hungary; by the János Bolyai Research Scholarship of the Hungarian Academy of Sciences and by the Korányi Research Scholarship; financial supports are gratefully acknowledged.

[11] Andud, D., Mat, M. F., Manurung, Y. H. P., Saidin, S., Nordin, N., Muhammad, N., Laitner, M. "Fatigue Life Enhancement of Transverse and Longitudinal T-Joint on Offshore Steel Structure HSLAS460G2+M using Semi-automated GMAW and HFMI/ PIT", presented at MATEC Web of Conferences, 269, IIW 2018 - International Conference on Advanced Welding and Smart Fabrication Technologies, Article Number: 06001, 2019. https://doi.org/10.1051/matecconf/201926906001

[12] Edgren, M., Barsoum, Z., Åkerlind, K., Al-Emrani, M. "Evaluation of HFMI as a Life Extension Technique for Welded Bridge Details", Procedia Structural Integrity, 19, pp. 73-80, 2019. https://doi.org/10.1016/j.prostr.2019.12.009

[13] Gölz, L., Breunig, S., Kuhlmann, U. "Sustainable steel and composite bridges through increased lifetime by fatigue treatment", IOP Conference Series: Materials Science and Engineering, 615, Article Number: 012117, 2019 https://doi.org/10.1088/1757-899X/615/1/012117

[14] Harati, E., Svensson, L.-E., Karlsson, L. "Improving fatigue strength of welded $1300 \mathrm{MPa}$ yield strength steel using HFMI treatment or LTT fillers", Engineering Failure Analysis, 79, pp. 64-74, 2017. https://doi.org/10.1016/j.engfailanal.2017.04.024

[15] Ruiz, H., Osawa, N., Rashed, S. "A practical analysis of residual stresses induced by high-frequency mechanical impact post-weld treatment", Welding in the World, 63, pp. 1255-1263, 2019. https://doi.org/10.1007/s40194-019-00753-w

[16] Schubnell, J., Eichheimer, C., Ernould, C., Maciolek, A., RebeloKornmeier, J., Farajian, M. "The influence of coverage for high frequency mechanical impact treatment of different steel grades", Journal of Materials Processing Technology, 277, Article Number: 116437,2020 .

https://doi.org/10.1016/j.jmatprotec.2019.116437

[17] Marquis, G. B., Barsoum, Z. "IIW Recommendations for the HFMI Treatment, For Improving the Fatigue Strength of Welded Joints", Springer, Singapore, 2016 https://doi.org/10.1007/978-981-10-2504-4

[18] Haagensen, P. J., Maddox, S. J. "IIW Recommendatios on Post Weld Improvement of Steel and Aluminium Structures", IIW Commission XIII, The International Institute of Welding, XIII-1815-00, 2001. 
[19] Weich, I., Ummenhofer, T., Nitschke-Pagel, T., Dilger, K., Chalandar, Eslami, H. "Fatigue Behaviour of Welded High-Strength Steels after High Frequency Mechanical Post-Weld Treatments", Welding in the World, 53, pp. R322-R332, 2013. https://doi.org/10.1007/BF03263475

[20] Yildirim, H. C., Marquis, G. B. "Overview of Fatigue Data for High Frequency Mechanical Impact Treated Welded Joints", Welding in the World, 56, pp. 82-96, 2012. https://doi.org/10.1007/BF03321368

[21] Yildirim, H. C. "Design aspects of high strength steel welded structures improved by high frequency mechanical impact (HFMI) treatment", Doctoral Dissertation, Aalto University, 2013. [online] Available at: https://aaltodoc.aalto.fi/handle/123456789/11146 [Accesseed: 20 March 2020]

[22] Hobbacher, A. "Formulae for Stress Intensity factors, Recommendations for Fatigue Design of welded joints and components", International Institute of Welding, Genoa, Italy, IIW document XIII-1965-03 / XV-1127-03, 2004.

[23] Yekta, R. T. "Acceptance Criteria for Ultrasonic Impact Treatment of Highway Steel Bridges", MASc, University of Waterloo, 2012. [online] Available at: http://hdl.handle.net/10012/6933 [Accessed: 20 March 2020]

[24] Kuhlmann, U., Dürr, A., Bergmann, J., Thumser, R. "Effizienter Stahlbau aus höherfesten Stählen unter Ermüdungsbeanspruchung" (Efficient steel construction made of high-strength steels under fatigue stress), Forschungsvereinigung Stahlanwendung, Düsseldorf, Germany, 2006. (in German)
[25] Okawa, T., Shimanuki, H., Funatsu, Y., Nose, T., Sumi, Y. "Effect of preload and stress ratio on fatigue strength of welded joints improved by ultrasonic impact treatment", Welding in the World, 57, pp. 235-241. 2013. https://doi.org/10.1007/s40194-012-0018-y

[26] Kuhlmann, U. "Experimentelle Untersuchungen zur ermüdungssteigernden Wirkung des PIT-Verfahrens"(Experimental studies on the fatigue strength increasing effect of the PIT post weld treatment), PITEC GmbH, Heudorf, Germany, 2009. (in German)

[27] Lihavainen, V. M., Marquis, G., Statnikov, E. S. "Fatigue Strength of a Longitudinal Attachment Improved by Ultrasonic Impact Treatment", Welding in the World, 48, pp. 67-73, 2004. https://doi.org/10.1007/BF03266434

[28] Huo, L., Wang, D., Zhang, Y. "Investigation of the fatigue behaviour of the welded joints treated by TIG dressing and ultrasonic peening under variable-amplitude load", International Journal of Fatigue, 27(1), pp. 95-101, 2005.

https://doi.org/10.1016/j.ijfatigue.2004.05.009

[29] Mori, T., Shimanuki, H., Tanaka, M. "Influence of Steel Static Strength on Fatigue Strength of Web-Gusset Welded Joints with UIT", Journal of JSCE, 3(1), pp. 115-127, 2015. https://doi.org/10.2208/journalofjsce.3.1_115

[30] Weich, I. "Ermüdungsverhalten mechanisch nachbehandelter Schweißverbindungen in Abhängigkeit des Randschichtzustands" (Fatigue behavior of mechanically treated welded joints depending on the surface condition), $\mathrm{PhD}$ dissertation, Technischen Universität Carolo-Wilhelmina, 2008. (in German) 